\title{
Será que o SIADAP responde adequadamente às necessidades de avaliação do desempenho
} na Administração Pública?

\author{
Elsa Barbosa \\ elsa.barbosa@ipbeja.pt \\ Escola Superior Tecnologia e Gestão/Instituto Politécnico de Beja \\ Inês Parrinha \\ ines.parrinha@ulsba.min-saude.pt \\ Unidade Local de Saúde do Baixo Alentejo, EPE / Serviço de Recursos Humanos
}

\begin{abstract}
Resumo
A avaliação de desempenho na Administração Pública, nomeadamente o Sistema Integrado de Avaliação do Desempenho (SIADAP), foi o impulsor de uma Gestão por Objectivos, proporcionando uma viragem na Administração Pública.

O SIADAP, tornou-se num dos mais importantes sistemas de gestão dentro das organizações por ser a única ferramenta de gestão capaz de promover a ascensão na carreira profissional dos colaboradores.

Na Unidade Local de Saúde do Baixo Alentejo (ULSBA), EPE após cinco anos de implementação do SIADAP, tornou-se oportuno e até necessário fazer uma introspecção sobre todo o processo para evitar desfasamentos ao que é proposto.

O desígnio da realização deste trabalho de investigação foi minimizar os constrangimentos identificados e proporcionar a todos os colaboradores um maior e melhor rigor na aplicabilidade do SIADAP, com o intuito de fortalecer a cadeia de valor público na ULSBA, EPE.

O presente trabalho de investigação teve por base a realização de questionários aos avaliadores e avaliados sobre o impacto real do referido sistema de avaliação, quer a nível profissional, quer a nível psicológico. Os questionários encontravam-se divididos por matérias e foram enviados via e-mail a um universo de aproximadamente 250 colaboradores.

Os resultados obtidos foram do âmbito da Aplicação Geral do Sistema, do Conselho Coordenador de Avaliação (CCA), dos Avaliadores e dos Avaliados, nomeadamente a necessidade de criar um sistema de informação para monitorização geral dos objectivos propostos, necessidade de reforço de intervenção do CCA, carência de atitude proactiva dos avaliadores, descrença no sistema vigente por parte dos avaliados, entre outros.
\end{abstract}

Palavras chave: Avaliação do Desempenho, SIADAP, ULSBA, Gestão por Objectivos, Administração Pública

\section{Introdução}

O estudo apresentado incidiu sobre colaboradores da extinta Sub-Região de Saúde de Beja (SRS), responsável pelos cuidados primários do distrito de Beja. A escolha da amostra recaiu sobre estes colaboradores por se entender ser uma "fotografia" da aplicação do Sistema Integrado de Avaliação do Desempenho (SIADAP).

Em Outubro de 2008, com a extinção da SRS Beja, criou-se a Unidade Local de Saúde do Baixo Alentejo, EPE (ULSBA), que abrange os cuidados hospitalares e os cuidados primários do distrito de Beja, com excepção do Centro de Saúde de Odemira. 
Pelo facto do número de colaboradores abrangidos por este sistema de avaliação, ter triplicado, tornou-se necessário fazer uma análise, à forma de como está a ser aplicado todo o processo inerente a este sistema de avaliação, nomeadamente os efeitos que possa estar a causar quer a nível do impacto psicológico, quer a nível do desempenho profissional.

\section{Objectivo Geral}

O desígnio principal da criação do SIADAP foi o gerar valor público na Administração Pública, através de uma gestão por objectivos, que sugere uma relação entre os objectivos da organização e os objectivos individuais dos colaboradores. Esta interacção permite clarificar a importância do colaborador na empresa e consequentemente responder às necessidades dos stakeholders externos, de uma forma mais eficaz e eficiente.

Este trabalho de investigação propõe uma introspecção de como está a decorrer todo o processo de avaliação, para que não existam desfasamentos ao que é proposto. Ainda indica algumas sugestões para minimizar os hiatos existentes de forma a proporcionar a todos os colaboradores, abrangidos por este Sistema de Avaliação, um maior e melhor rigor na aplicabilidade do SIADAP, nos anos futuros.

Ao nível do órgão de gestão, a informação extraída deste trabalho de investigação, propôs fornecer informação objectiva, sobre as virtualidades e possíveis falhas de aplicação do Sistema, no sentido de atempadamente serem efectuadas as correcções necessárias que permitam a calibragem do mesmo e garantir a máxima equidade entre colaboradores.

\section{Secção 1}

\section{O Novo Paradigma / SIADAP}

O SIADAP, inicialmente legislado pela Lei $\mathrm{n}^{0}$ 10/2004 de 22 de Março e Decreto Regulamentar $n^{\circ} 19-\mathrm{A} / 2004$ de 14 de Maio surgiu subjacente a uma nova perspectiva de gestão, baseada numa avaliação por objectivos.

A avaliação por objectivos foi defendida nos anos 80 pelo autor Peter Ducker, propôs que os objectivos dos colaboradores devem estar alinhados com os objectivos da organização e que 
devem ser objectivos específicos, mensuráveis, atingíveis, realistas e com prazo definido (Modelo "SMART”).

A Lei referida anteriormente foi aplicada durante 4 anos de avaliação de desempenho (de 2004 a 2007), mas por ser uma Lei que apresentava algumas lacunas, provocou divergências na sua aplicabilidade. No decorrer destes 4 anos sentiu-se necessidade de ajustar a Lei às necessidades e modernizá-la, tornando-a num instrumento de gestão muito particular.

No final do ano 2007 surgiu então a Lei no 66-B/2007 de 28 de Dezembro, designada: Sistema

\section{Integrado de Gestão de Avaliação do Desempenho na Administração Pública.}

Com esta Lei foram igualmente aprovados documentos, para auxiliar a operacionalização do processo de avaliação, tais como, o modelo de ficha de monitorização do desempenho, o modelo de ficha de reformulação de objectivos e as listas de competências por grupos profissionais Portaria $n^{\circ}$ 1633/2007 de 31 de Dezembro.

Com a nova legislação de Avaliação de Desempenho na Administração Pública, surgiu uma nova visão sobre a Administração Pública, subjacente à gestão, em que tudo deve ser transparente sempre com o objectivo de servir o cliente com uma lógica de fora para dentro, sem esquecer a perspectiva da Administração, nos termos da lealdade à legislação e ao primado do serviço público.

\section{Secção 2}

\section{Metodologia Utilizada}

Elaboram-se 2 questionários, um para avaliadores e outro para avaliados, divididos nos parâmetros de aplicação do SIADAP.

Os questionários foram enviados via e-mail a aproximadamente 250 colaboradores da extinta SRS Beja, avaliadores e/ou avaliados pelo SIADAP, divididos nos seguintes grupos profissionais: Médicos (apenas como avaliadores), Técnicos Superiores, Técnicos Superiores de Saúde, Técnicos de Informática, Coordenadores Técnicos, Assistentes Técnicos e Assistentes Operacionais.

O grau de confiança obtido no questionário dos avaliadores foi de $90 \%$ e dos avaliados foi de $65 \%$, com uma margem de erro de $10 \%$. 


\section{Secção 3}

\section{Dimensões Analisadas}

Os questionários aplicados foram divididos por dimensões, nomeadamente:

- Efeitos da Avaliação

Com a aplicação do SIADAP e a vigência da Lei no 12-A/2008 de 27 de Fevereiro (LVCR), a avaliação do desempenho tornou-se num instrumento, por excelência, de progressão na carreira. Sendo este um dos aspectos mais salientados no universo dos avaliadores. Já os avaliados para além de mencionarem as alterações de posicionamento remuneratório também salientam a criação dos subsistemas (SIADAP 1, 2 e 3), que implicou a divisão de universos definidos para atribuição de quotas, entre dirigentes e restantes funcionários.

\section{- Impacto Psicológico dos Colaboradores}

De acordo com a análise feita, em sequência da aplicação do SIADAP, os aspectos mais notados ao nível do impacto psicológico dos colaboradores foram: alteração de humor, aumento de pressão, desmotivação e desagrado.

Apenas duas respostas foram opositoras ao nível do impacto psicológico, ao afirmar que a gestão por objectivos proporcionou uma maior clareza do posicionamento de cada colaborador na empresa e consequentemente uma maior satisfação dos clientes/ utentes.

- Nível de Desempenho Profissional

"Com a aplicação do SIADAP, que aspectos mais relevantes se fazem notar ao nível de desempenho profissional?". A resposta a esta questão foi unânime ao responderem que causou um "maior empenho profissional".

É interessante analisar a ambiguidade detectada relativamente ao parâmetro anterior. Como é que os aspectos negativos mencionados ao nível do impacto psicológico, reflectem num maior empenho profissional? Pressupomos que os colaboradores quando pressionados a cumprir 
objectivos que lhe são propostos, esforçam-se mais, mesmo que seja com desagrado, ou ainda se deve ao facto da competitividade ser cada vez maior entre colaboradores proporcionando um empenho notório. Mas será que este aumento de empenho associado aos aspectos negativos referidos ao nível do impacto psicológico, gera valor público?

- Entrevista de Discussão dos Resultados/Objectivos

Em ambos os questionários interrogou-se se houve entrevista de discussão de objectivos entre avaliador e avaliado. Detectou-se que de um modo geral realizou-se a reunião de avaliação onde foram negociados os objectivos. Esta é uma fase da avaliação demasiado importante, pois é aqui que o colaborador tem possibilidade de se pronunciar sobre a avaliação que lhe é atribuída ou proposta e negociar os objectivos em conformidade com as suas competências (profissionais e pessoais). A realização desta entrevista liberta o avaliador de possíveis constrangimentos, por exemplo, a acusação de definir objectivos inatingíveis ou descrever objectivos que não estejam de acordo com o conteúdo funcional do trabalhador.

- Monitorização de Resultados/Objectivos

Os avaliadores quando questionados sobre as dificuldades na aplicabilidade do SIADAP, a monitorização dos objectivos foi o obstáculo mais notado. A ausência de instrumentos que permitam a parametrização dos objectivos, proporciona uma avaliação subjectiva.

Para ultrapassar esta questão, os avaliadores aquando da definição dos objectivos, devem prever a sua monitorização de forma a criarem à partida objectivos mensuráveis.

Os avaliadores quando questionados se, " $80 \%$ dos colaboradores à sua responsabilidade atingem os objectivos propostos", a resposta afirmativa dos mesmos foi unânime.

Ao estabelecer uma relação entre a questão da monitorização dos objectivos e a esta questão, acredita-se que os avaliadores continuam a avaliar com base em incidentes críticos. Se não existem mecanismos de monitorização, mas os trabalhadores atingem em $80 \%$ os objectivos que lhe são propostos, então em que base está a ser feita esta avaliação? E talvez agora se tenha 
encontrado resposta para os aspectos negativos que foram mencionados ao nível do impacto psicológico.

Senão houver monitorização de objectivos e uma orientação na aquisição ou desenvolvimento das competências propostas, a avaliação de desempenho deixa de ter "base de sustentação" e segue uma orientação parcial.

\section{- Definição de Objectivos}

As respostas dividiram-se quanto à questão: "Os objectivos sofreram alteração ao longo dos 4 anos?" 40\% das respostas foram Sim, fundamentaram que houve alteração de funções e 55\% responderam que $N a ̃ o$, estes não justificaram; $5 \%$ não responderam.

Em suma, na maioria das situações, não se está a verificar alteração de objectivos, o que faz com que o colaborador se acomode aos objectivos definidos.

É legitimo questionar: se há 4 anos que o funcionário não precisa de se esforçar mais, será que está acomodado ou que atingiu o seu limite?

O avaliador e as chefias da organização têm um papel primordial na análise dos objectivos a definir de ano para ano.

"Os objectivos que definiu foram com que intuito?". Com a resposta a esta questão provou-se claramente, que os avaliadores têm consciência que é preciso motivar os colaboradores (55\% das respostas) aquando da definição dos objectivos.

Mas que mecanismos utilizam para obter a motivação esperada?

Com a resposta a questões anteriores, detectou-se que os colaboradores não estão motivados, logo existe um hiato entre a pretensão dos avaliadores e o desempenho profissional dos colaboradores.

Conjectura-se que a motivação dos colaboradores é um factor essencial de criação de valor público nas organizações. 
- Competências

$\mathrm{Na}$ dimensão das competências do questionário, há uma preocupação clara por parte dos avaliadores ao tentarem adaptar as competências ao perfil do colaborador.

O mecanismo que utilizaram para o desenvolvimento e/ou aquisição das competências definidas, foi a motivação e a formação profissional.

- Continuidade na Aplicação do SIADAP

Os avaliadores quando questionados sobre a continuidade da aplicação deste Sistema de Avaliação, dividiram-se em $80 \%$ respostas para o Sim e $20 \%$ para o Não.

Os avaliados dividem-se na resposta a esta questão, 45\% são da opinião que não devia ter continuidade e 55\% concordam com a aplicação deste Sistema de Avaliação.

Uma vantagem apresentada pelos avaliadores, é o facto de ser um Sistema que permite a diferenciação entre colaboradores e ajuda a definir a posição que cada colaborador ocupa dentro da instituição.

Como desvantagens, realçam o tempo que este Sistema requer. Os avaliados ainda acrescentam que é um Sistema demasiado subjectivo e gerador de conflitos.

Estas desvantagens apontadas pelos avaliados devem ser realçadas, uma vez que pode ser um indicador de desilusão e descrença no Sistema de Avaliação em vigor. É importante que o avaliador seja informado da percepção dos avaliados para tentar atenuar as desvantagens apontadas.

\section{Secção 4}

\section{Reflexões / Sugestões}

A análise feita aos parâmetros anteriores, conduziu à reflexão e identificação de alguns gap's que devem ser minimizados, de forma a proporcionar uma melhor aplicabilidade do SIADAP na organização.

\section{1) Quebrar a Resistência}


Constatou-se que existe uma enorme resistência, por parte dos colaboradores, em discutir aspectos relativos ao Sistema de Gestão de Avaliação de Desempenho na Administração Pública. Pressupõe-se que esta resistência deve-se à descrença que existe no sistema.

\section{2) Monitorização de Objectivos}

A monitorização dos objectivos é um dos aspectos mais importantes deste novo processo de gestão de avaliação, é um instrumento fundamental para a aplicação do SIADAP. É a partir da monitorização dos objectivos que a avaliação dos resultados deve ser atribuída.

Este controle material permite atribuir uma avaliação justa baseada em dados concretos que podem ser analisados quer pelo avaliador quer pelo avaliado.

Existem vários mecanismos que se podem identificar para efectuar a monitorização, como por exemplo, a ficha de monitorização e/ou reformulação de objectivos (instrumento disponível na Portaria $n^{0}$ 1633/2007 de 31/12), aplicações informáticas, mapas, listagens, estatísticas, inquéritos, questionários, a criação de um "cliente mistério".

\section{3) Alteração de Objectivos}

Foi notório que na maioria dos casos, os objectivos permaneceram inalteráveis ao longo destes 4 anos. O facto de durante 4 anos, permanecerem os mesmos objectivos e os mesmos critérios de superação, é desmotivador e céptico.

\section{4) Acções de Formação}

Diagnosticou-se que a falta de formação dos avaliadores e a falta de informação dos avaliados é uma realidade que tem de ser ultrapassada. A formação que ocorreu aquando da anterior legislação, mostra-se agora desfasada no tempo e manifestamente insuficiente.

É essencial que a organização promova a formação profissional apontada pelos avaliadores e avaliados na ficha de avaliação.

\section{5) Promover a Articulação entre Objectivos e Competências}

Uma vez que a avaliação final do desempenho é baseada em resultados e competências, é importante que haja uma articulação entre estes dois parâmetros. 
É necessário um maior rigor na definição dos objectivos individuais e um acréscimo da preocupação na adequação das competências escolhidas.

\section{6) Impulsionar a Aquisição ou o Desenvolvimento de Competências}

A escolha das competências profissionais e pessoais deve ser individualizada e estimulada durante o ano da avaliação.

Esta aquisição ou desenvolvimento de competências pode ser feita através de acções de formação, de acompanhamento personalizado, de apoio no decorrer das suas actividades / tarefas. É importante que o colaborador se sinta útil, eficiente e eficaz.

\section{7) Conteúdo Funcional dos Avaliadores}

Ao longo de 4 anos a acompanhar de perto todo o processo inerente ao SIADAP, provou-se que este sistema de avaliação é um processo muito moroso e que adicionado à responsabilidade de um líder, torna-se difícil de aplicar.

Esta mudança de visão da Administração Pública, não só tem o intuito de gerar valor público, como também desenvolver capacidades de liderança às chefias das organizações.

É muito importante que se desenvolva o exercício efectivo do conteúdo funcional do responsável e os seus objectivos, e que estes sejam de conhecimento em toda a organização, para que no terreno todos tenham consciência da relação hierárquica que devem estabelecer.

Muitas vezes a falta de recursos humanos implica que o responsável tenha que assumir outras funções, descurando questões que só a ele compete, nomeadamente a avaliação de desempenho.

\section{8) Promover a Motivação}

Deverá apelar-se a todos os avaliadores, a incentivar, motivar os colaboradores à sua responsabilidade, através de reforços positivos. O colaborador aumenta a auto-estima para desempenhar as suas funções, que provocará uma melhor satisfação na prestação de serviços aos utentes, este é um aspecto primordial que se deve continuar a estimular na Administração Pública.

\section{9) Acesso à Informação}


A criação de um sub-site na intranet das organizações pode ser a solução parcial, no acesso à informação. Neste sub-site devem estar disponíveis, todos os documentos inerentes ao processo de avaliação de desempenho, o calendário previsto para cada uma das fases do processo e disponibilizar um espaço onde os colaboradores possam colocar algumas questões ou dúvidas sobre o SIADAP, esta é uma forma de "chegar" a todos os colaboradores, e de certa forma, colmatar as dificuldades que vão surgindo no dia-a-dia de cada trabalhador.

\section{0) Contagem de Pontos Atribuídos pela Avaliação de Desempenho}

O avaliador deve ter conhecimento do total de pontos de cada um dos seus avaliados. Esta informação pode ser importante na atribuição da classificação final, pode ser utilizada como um critério de desempate entre colaboradores.

\section{Conclusão}

Face ao objectivo inicial do trabalho, as principais conclusões retiradas, são:

\section{1) Aplicação Geral do Sistema}

- Insuficiente informação / Escassez de formação dos avaliadores e avaliados;

- Inexistência de acompanhamento da aplicação do sistema pelas chefias de topo;

- Necessidade de criar um sistema de informação para monitorização geral do sistema.

\section{2) Conselho Coordenador de Avaliação de Desempenho (CCA)}

- Necessidade de reforço de intervenção do CCA, por ser a este órgão que compete assegurar uma aplicação objectiva e harmónica do SIADAP.

\section{3) Avaliadores}

- Carência de atitude proactiva na aplicabilidade deste sistema de avaliação, fomentando um maior rigor, quer na definição de objectivos quer na monitorização e/ou reformulação de objectivos;

- Promover a motivação nos colaboradores à sua responsabilidade;

- Omissão na aquisição e desenvolvimento de competências no âmbito do domínio saber/ser e saber/fazer; 
Investigação e Intervenção em Recursos Humanos 2010 - Dilemas de uma sociedade em transformação

Escola Superior de Ciências Empresariais do Instituto Politécnico de Setúbal 23 e 24 de Setembro de 2010

- Impulsionar a proficiência e a criação de um valor público eficiente e eficaz.

\section{4) Avaliados}

- É notória a conformidade com o sistema, o que implica um papel passivo no decorrer de todo o sistema de avaliação;

- Transmitem descrença no sistema vigente.

Conclui-se que com a informação do presente estudo, está-se mais apto para promover as necessárias correcções e/ou melhorias na implementação do SIADAP na ULSBA/EPE, e assim, enriquecer a cadeia de valor na prestação de um serviço público.

\section{Bibliografia}

TEIXEIRA, Sebastião (1998). Gestão das Organizações. Alfragide: Editora McGraw-Hill.

Documentação da Formação: Diploma de Especialização em Avaliação do Desempenho. Oeiras: INA

Barbosa, Elsa e Parrinha, Inês (2010). O Impacto do Sistema de Avaliação do Desempenho. Recursos Humanos Magazine, Março-Abril 2010, pp.32-36.

Corporate Advisor. Projectos Especiais, Sistema de Avaliação de Desempenho, disponível em http://www.corporate.jpleconomistas.com/Textos/AvaliacaoDesempenho.pdf, pp.1-5. (consultado em 16 de Outubro de 2009) 